\title{
Erratum to: Does paternal mental health in pregnancy predict physically aggressive behavior in children?
}

\author{
Anne Lise Kvalevaag • Paul G. Ramchandani • \\ Oddbjørn Hove · Malin Eberhard-Gran · Jörg Assmus • \\ Odd E. Havik · Børge Sivertsen $\cdot$ Eva Biringer
}

Published online: 25 December 2014

(C) Springer-Verlag Berlin Heidelberg 2014

\section{Erratum to: Eur Child Adolesc Psychiatry (2014) \\ 23:993-1002 \\ DOI 10.1007/s00787-014-0587-y}

Unfortunately, the names of fifth and sixth authors were misspelt in the original article. The correct names should be Jörg Assmus and Odd E. Havik.

Further, the author affiliations were omitted. The correct list of author affiliations reads as below:

A. L. Kvalevaag, O. Hove, B. Sivertsen, E. Biringer

Department of Psychiatry, Helse Fonna HF, P.O. box 2170,

5504 Haugesund, Norway

e-mail: anne.lise.kvalevaag@ @else-fonna.no

P. G. Ramchandani

Academic Unit of Child and Adolescent Psychiatry, Imperial College, London, UK

The online version of the original article can be found under doi:10.1007/s00787-014-0587-y.

A. L. Kvalevaag $(\bowtie) \cdot$ O. Hove $\cdot$ B. Sivertsen $\cdot$ E. Biringer Department of Psychiatry, Helse Fonna HF, P.O. box 2170, 5504 Haugesund, Norway

e-mail: anne.lise.kvalevaag@ helse-fonna.no

P. G. Ramchandani

Academic Unit of Child and Adolescent Psychiatry, Imperial

College, London, UK

\section{Eberhard-Gran}

Division of Mental Health, Norwegian Institute of Public Health, P. B. 4404 Nydalen, 0403 Oslo, Norway

M. Eberhard-Gran

Health Services Research Center, Akershus University Hospital, Oslo, Norway
M. Eberhard-Gran

Division of Mental Health, Norwegian Institute of Public Health, P. B. 4404 Nydalen, 0403 Oslo, Norway

M. Eberhard-Gran

Health Services Research Center, Akershus University Hospital, Oslo, Norway

\section{J. Assmus}

Center for Clinical Research, Haukeland University Hospital, 5021 Bergen, Norway

O. E. Havik

Department of Clinical Psychology, University of Bergen, Christiesgt. 12, 5020 Bergen, Norway

B. Sivertsen

Division of Mental Health, Norwegian Institute of Public Health, Kalfarveien 31, 5018 Bergen, Norway

B. Sivertsen

Uni Health, Uni Research, Bergen, Norway.

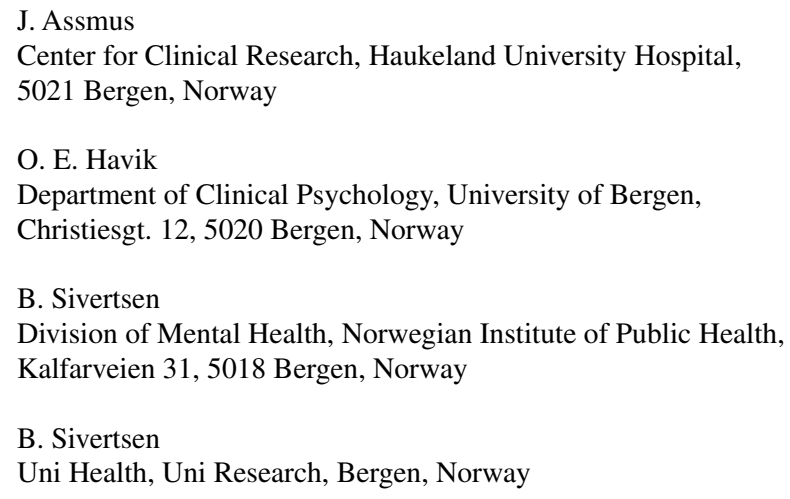

